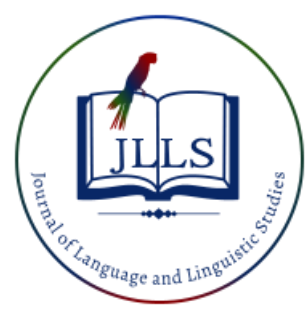

Available online at www.jlls.org

JOURNAL OF LANGUAGE AND LINGUISTIC STUDIES

ISSN: 1305-578X

Journal of Language and Linguistic Studies, 17(4), 1684-1694; 2021

\title{
The fine line between compounds and portmanteau words in English:
}

\section{A prototypical analysis}

\begin{abstract}
Hicham Lahlou $^{\text {a }}$ iD, Imran Ho-Abdullah ${ }^{\text {b }}$ iD
${ }^{a}$ School of Humanities, Universiti Sains Malaysia, Malaysia

APA Citation:

${ }^{b}$ School of Language Studies and Linguistics, Universiti Kebangsaan Malaysia, Malaysia

Lahlou, H., \& Abdullah, I.H. (2021). The fine line between compounds and portmanteau words in English: A prototypical analysis. Journal of Language and Linguistic Studies, 17(4), 1684-1694. Doi: 10.52462/jlls. 123

Submission Date:18/04/2021

Acceptance Date:24/07/2021

Abstract

The current paper investigates two productive morphological processes, namely compounds and portmanteau words (or blends). While compounds, a productive, regular and predicable morphological process, have received much attention in the literature, little attention was paid to portmanteau words, a creative, irregular and unpredictable word formation process. The present paper aims to find the commonalities and differences between these morphological devices, using Rosch et al.'s $(1975 ; 1976)$ theory of prototypes and basic-level categories to achieve this goal. This theory will also be employed to discuss the literature on the word formation mechanisms under investigation and propose a new categorization approach to these neologisms. The analysis suggests that compounds and blends compare and contrast and that the distinctions between them are blurry. The analysis confirms that a prototypical approach is well suited to compounds and blends in English. This has implications for future research into English word-formation processes in general and compounds and blends precisely.
\end{abstract}

Keywords: English; compounds; blends; prototypes; periphery; basic-level category

\section{Introduction}

Word-formation is among the most dynamic processes that enrich the vocabulary of English. It enables a language user to construct novel words out of the existing ones to express newly experienced situations (Hamawand, 2011). Much research has been done on word-formation; however, they have mainly been concerned with word-formation processes that conform to regular grammatical and morphological patterns, notably affixation and compounding. Other morphological processes, such as clipping and blending, were believed to be irregular (Aronoff, 1976; Bauer, 2006). Consequently, they were excluded from morphology (Dressler, 2000; Mattiello, 2013) and received little attention given that they are the outcome of a creative, irregular process (Hamans, 2010). Thus, compared to blends, the literature on these morphological devices places a greater emphasis on compounds. This is because blends, compared with compounds, are combinations of parts of words, not complete words or morphemes. They generally do not adhere to morphogrammatical rules. They are the outcome of euphony. Furthermore, they are not universal, and just a tiny percentage of them become lexicalized. 
Despite this, blends significantly contribute to vocabulary enrichment. They are a productive and creative morphological process, given that English speakers tend to create them in everyday use and construct them to reflect their new concepts. Therefore, ruling out this essential mechanism as irregular may leave many data on how language users form and understand neologisms unexplained. In this regard, Dressler (2000) contends that research should concern productive and prototypical morphology and extra grammatical and peripheral morphology. Comprehending less prototypical morphological processes helps us understand the prototypical ones better. Research on peripheral morphology ought to "be elevated to the rank of a systematic study of basic questions which are likely to illuminate research in morphology at large" (Dressler, 2000, p. 8). Other studies, on the other hand, revealed that blends are constrained by semantic, syntactic, and prosodic constraints and, as a result, should not be removed from 'grammatical morphology' (e.g., Plag, 2003). In the same vein, Trommer and Zimmermann (2012) suggested that the forming of blends should not be classified as extragrammatical but as a prosodic morphology-based component. Also, based on corpus-based research, blends are not unpredictable. Their features are not only discernible but are also deeply entrenched in cognitive but essentially psycholinguistic and probabilistic processes (Gries, 2012).

The approaches employed in categorizing morphological processes in general and compounds and blends in particular and excluding blends from grammatical and morphological research were primarily traditional, or rather Aristotelian. Within this framework, an entity can be a category member only if it meets all the necessary and sufficient conditions. The entity can either be a member or a nonmember of the category. Blends are considered non-members of grammar and morphology because they are composed of only parts of words rather than whole words or morphemes. The authors believe that an approach that incorporates all of the factors that contribute to creating a coinage, recognizes the fuzzy area between members of a category, and emphasizes the conceptual underpinnings of a category and its members would provide a deeper understanding of their construction as well as comprehension. The present paper aims to compare and contrast compounds and blends, discuss the literature on them, and propose a new approach to them. The current study applies Rosch et al.'s $(1975 ; 1976)$ theory of prototypes and basic-level categories.

\section{Previous Research on Blends}

As discussed earlier, most literature on syntax and morphology rejects blends. Downing (1977) states that blends, in contrast to compounds, commonly consist of (almost) synonymous words. Compounds such as palm tree are acceptable and therefore lexicalized. She does agree, however, that certain blends are identical to compounds, but they are primarily onomatopoeic reduplications, as in drip-drip. Owing to their redundancy, these examples are unacceptable. Blends, according to Aronoff (1976), are oddities, not a universal feature of language. They are non-productive because they are not regularly derived. They are incomprehensible, as they are made up of meaningless splinters. Blends, according to Trask (1994), consist of arbitrary parts of words "chopped off and stitched together" (p. 16) and are frequently used to achieve a punning effect, such as in icecapade (a spectacular ice show) (Ginzburg et al., 1979). Blends, however, were only invented for this purpose in the earlier centuries and have become more common since the twentieth century and were thus considered a different type of word-formation (Adams 1973). Thus, blends have developed over time from puns to actual words that have enriched English speakers' daily vocabulary.

Beard (1998) asserts that blending, compared with grammatical derivation, is a process that tends to be conscious or logical, not grammatical. Whenever the reference constitutes part A and part $\mathrm{B}$, the lexical item that refers to it ought to consist of parts of the lexical units for $\mathrm{A}$ and $\mathrm{B}$. The word tangelo, for instance, is the result of converting the lexical items tangerine and pomelo into their splinters, that is, tang and elo. According to Stekauer (2001), word-formation patterns are one hundred per cent 
productive, regular and predictable. He postulates that compounds undergo the five suggested mental levels. At the same time, blends are only a two-step process: (i) it consists of coining an auxiliary "full version" naming unit constituent with the onomasiological model of word-formation, and (ii) the naming unit is formally reduced in an unpredictable (and thus irregular) way. The first step corresponds to compounding, and the second step is a lexical component. Thus, blends are unproductive because they are irregular and unpredictable.

According to Bauer (2003), it is unclear whether a blend is morphological. Bauer (2003) views the diverse morphological processes as a network, the central core of which embodies affixation, backformation, and neo-classical compounding; its exterior consists of clipping, blending, and forming acronyms. The line between morphology and non-morphology is not clear as morphology shades into other things. The central core is most clearly within morphology. If the connections between affixation processes and other processes are weak, it is more likely that they are non-morphological. Blends, for instance, are like acronyms because both processes are made up of splinters that are 'non-meaningbearing,' to use Bauer's (2003) expression.

Algeo (1978), on the other hand, challenges the assumption that words are well defined, arguing that the centre of every type of word-formation is evident while the borders may be blurry. The word scuba, for instance, is an acronym for self-contained underwater breathing apparatus. It is not easy, however, to establish whether Nabisco for National Biscuit Company is an acronym or another class of words. It is the ill-definition of the word classes within the traditional taxonomy that causes such confusion. Algeo (1978) proposes nine diachronic criteria. According to criterion iii (does it combine two or more etyma?) and criterion iv (does it shorten an etymon?), for instance, a compound is a word class consisting of two or more etyma that are not shortened, as in swimming pool. A blend, in contrast, is a word class, which comprises two or more etyma, with the shortening of at least one etymon, as in wintertainment (winter + intertainment).

Algeo's (1978) reference to the ill-definition of the word classes within the traditional taxonomy explains the source of the inappropriate morphological definitions and classifications. Gries (2004), in a similar vein, mentioned the difficulty in developing a proper definition of blends that distinguishes them from other word-formation processes. Blends are not only ill-defined because of their multiple complex forms, but there is also much disagreement on how to categorize them due to the lack of a specific blend scope (Bauer, 2012; Brdar, 2017). Blends' splinters take on various forms. For instance, they can be separated from the source word at a morpheme boundary, such as in transistor (from transfer and resistor), at a syllable boundary, such as cute in electrocute (from execute), or at both, as in smog (from smoke and fog) (Ginzburg et al., 1979).

More importantly, the literature on portmanteau words mainly focuses on the fact that they oppose universal grammatical word-formation characteristics and rules. Thus, they lie outside the boundaries of grammatical word formation (Dressler, 2000). Instead, they result from word creation rather than word formation because of their unpredictability (Renner, Maniez, \& Arnaud, 2012). In other words, they are formed through creativity, which generates neologisms without adhering to grammatical rules. Consequently, they are classified as a type of extragrammatical morphology marked by intentionality (Ronneberger-Sibold, 2010). This follows some scholars' argumentation that the study of morphological productivity should be limited to words generated unintentionally (Schutlink, 1961, cited in Aronoff \& Anshen, 1998), which eliminates the study of unproductive morphological processes, including lexical blends, which parallel more marginal word creation forms (Aronoff \& Anshen, 1998). While it is still unclear if blending is mainly a phenomenon of word creativity or a regular and predictable process of word formation (Beliaeva, 2019), the line between word formation and word creation is blurry. Blends, for example, tend to have more regularity than they appear at first glance (Renner, Maniez, \& Arnaud, 2012). Besides, the intentionality of which a term is coined cannot 
be measured (Haspelmath, 2010). As a result, it is fair to regard word formation and word creation as prototypical concepts (Bauer, 2001; Arnaud, 2013).

No one can deny the dissimilarities between compounds and blends, but the differences were overstated to the extent that these coinages were considered entirely different according to the classical approach. As mentioned earlier, this approach considers an entity a member of a category only if it meets all the necessary and sufficient conditions. Such criteria rule out certain members due to dissimilarities, no matter how limited they are and thus negatively affect the categorization of an object. A workable alternative to this perspective would view membership as "gradable" and recognizes degrees of category membership.

\section{Theoretical Framework}

Research on morphological processes and grammatical categories in general and compounds and blends, in particular, should not concern only well-defined prototypical examples but fuzzy categories as well. To this end, the current paper employs the theory of prototypes and basic-level categories developed by Rosch and her colleagues (Rosch et al., 1975; 1976) to investigate the word-formation processes under study. In contrast to the classical theory, prototype theory accounts for all members of a category. In the view of this theory, subcategories that are in the centre are clear, whereas those that are at the border are fuzzy and overlapping. These members form a continuum along which they bear a family resemblance to each other. Central members possess all the features, whereas peripheral members have only some features. A category member is then defined based on its resemblance to prototypes. Rosch performed several studies to test the hypothesis that certain birds are "birdier" than others. Just a few words were commonly classified as very good members of the category, according to the tests' findings, which confirmed this assumption. A robin is widely regarded as the most archetypal bird. This field study supports the hypothesis that humans do not regard category members the same as the classical approach suggests and that a member of a category does not have to possess all of the characteristics of an ideal example or "prototype" (Aitchison, 2012).

Categorization by prototypes may explain a variety of phenomena that are not explained by the classical categorization approach. In this regard, Geeraerts (2013) stated that a prototypical approach to categories has four primary characteristics. To begin with, prototypical categories exhibit varying degrees of representativeness. Second, they have a family resemblance structure in which more prototypical readings are surrounded by a radial amount of aggregate and overlapping readings. Finally, they are blurred at the border; certain entities may not be clear members of the category or may be of less clarity than good examples. Finally, a group of essential features cannot define prototypical categories (Geeraerts, 2013).

Berlin et al. (2013) suggest that speakers of Tzeltal name plants and animals at the basic level, which lies in the middle of the folk taxonomic hierarchy. For instance, oak and rabbit, at the genus level, are psychologically more basic and salient than post oak and cottontail rabbit at the species level in the taxonomic hierarchy. Similar findings by Rosch et al.'s (1976) study confirmed that psychologically most basic categories lie in the middle of a classification hierarchy. Compared with basic-level categories (for example, chair, car), superordinate categories (furniture, vehicle) share a smaller number of properties, and subordinate categories (kitchen chair, sports car) consist of numerous features that overlap with other subordinate categories of the basic-level category. The category kitchen chair, for instance, has the largest number of features with other types of chairs (Rosch et al. 1976). The current study draws on examples of compounds and blends from earlier works on these neologisms to investigate the commonalities, differences, and blurry line between compounds 
and blends, as well as to facilitate congruent development of linguistic argumentation on these coinages.

\section{Data Analysis and Discussion}

The most apparent differences between compounds and lexical blends are differences in grammatical and morphological regularities, form completeness and generation of novel affixes. In other words, blending is less regular, predictable and productive than compounding. This is because compounds are composed of complete etymons or complete (source) words, whereas blends comprise splinters, shortened etymon(s) or parts of lexical source words (e.g., Adams 1973; Algeo, 1978; Kemmer, 2003; Mattiello, 2013). The compound breakfast, for instance, is composed of free morphemes, whereas the blend ballute (balloon + parachute) consist of one free morpheme and a splinter. As previously said, being formed of parts of words, blends, compared with compounds, were categorized as an irregular and unpredictable word-formation process. Although compounds are more productive than blends (for example, Bauer, 1983; Trask 1994; Gries, 2012), blends, unlike compounds, can generate new affixes, such as -gate (from Watergate), -aholic (from alcoholic) and burger (from hamburger).

The most remarkable parallels between compounds and blends, on the other hand, lie in the fact that both compounding and blending use existing lexemes to create new ones. They share the point of reference and go through a similar conceptual process. For a language user to understand a blend, they should identify the source words. They generally make sense of a blend connected with its equivalent compound, which they need to be familiar with (cf. Lehrer, 1996). A hearer, for instance, can only comprehend the sense of the blend nucleonics if they know the senses of the source words nucleon and electronics. More importantly, both coinages share the same semantic and conceptual processes. This is because two or more senses and mental images merge to construct a new sense. In forming the blend Chunnel, for example, the senses of Channel and tunnel combine.

Notwithstanding the morphological differences between prototypical compounds and prototypical blends in terms of form, there are some blends where only one etymon is truncated. It is not easy to differentiate between the two word-formation processes (Bauer, 1983). The blend breathalyser (breadth + analyser), for instance, bears significant similarity to a compound because they are composed of one free morpheme and a shortened etymon. Given such a resemblance, it is difficult for a hearer to determine whether a case like this is a compound or a blend.

Another challenge to the claimed 'absolute' difference between compounds and blends lies in the blends' ability to generate affixes, as mentioned earlier. As not all affixes are the product of blending, there is a linguistic debate on whether blending or other combining processes derive certain affixes. For example, the prefix info- gives rise to new words like infoglut, infodump and infonaut. It is challenging here to decide whether all these words are blends (Quinion, 1996). This confusion is the result of the existence of the truncated form info- in the target word, that is, infotainment, and the clipping of the word information, that is, info-. The affix deriving from blending may then create compounds like infoglut, blurring the difference between compounds and blends in terms of form and making it difficult to distinguish between them with no reference to the etymology of these words. Furthermore, some English words may be blends and neoclassical compounds. The lexical unit Eurocrat may be the product of a morphological process in which the clipping Euro- is combined with the Greek morpheme Kratos (power) or a blend of European and bureaucrat (Bauer, 1998).

A key problem with much of the literature is that while compounds were studied in terms of their syntactic, morphological, and/or semantic features, blends were examined in terms of their phonological and relatively morphological constituents. The findings of syntax-based studies added 
substantially to our understanding of headedness. For instance, the compound textbook is a type of books, and the blend keytainer is a form of container or small case for carrying keys. However, this kind of approach failed to account for exocentric (non-headed) compounds like cut-throat (a murderer) and blends such as tangerine. The grammatical approach, thus, did not only exclude blends, being grammatically irregular and of a phonological nature, but it was unsuccessful in explaining compounds, which are 'grammatically regular.'

Several linguists believe that blends should be studied in terms of phonology because they are produced on a phonological basis, that is, when the source words combined to form a blend have phonological similarity. Blends, excluding graphic blends like pollutitian from pollution and politician and affluenza from affluent and influenza, emerge in the oral channel, particularly when phonetically similar splinters of the underlying words are telescoped (Fandrych, 2008). Blends do not fit into morphological structure patterns as they do not contain morphemes "in the sense of recurrent minimal meaningful parts" but are made up of "phonological strings that trigger meaning" (Kemmer, 2003, p.77). More importantly, blends are better defined using prosodic categories (Plag, 2003). The most dominant (and prototypical) blends are those that are composed of the initial part of the first source word and the second part of the second source word (for example, Plag, 2003; Brdar-Szabó \& Brdar, 2008; Arndt-Lappe \& Plag, 2013), reflecting the formula $\mathrm{AB}+\mathrm{CD}=\mathrm{AD}$, as in smog from smoke and fog (Plag, 2003).

Lehrer's (2007) corpus of blends, in contrast, showed that the most prevalent kind of blend is one that consists of a combination of all the first source word and the splinter of the second source word, as in chattire (chat + satire). Other common kinds of blends, based on her corpus, were: blends comprising a part of the first word and the whole second word, as in squangle (from square and angle), blends made up of two splinters, such as psychergy (psychic and energy), and blends with phonetic or syllable overlap (for example, Cocacolonization (from CocaCola and colonization). Less popular uses of blends include a fusion of a source word inside the other source word, as in chortle (chuckle + snort) (Lewis Carroll), or contain partial overlap, with letters or phonemes emerging in both source words (e.g., wintertainment from winter and entertainment) (Lehrer, 2007).

Lehrer's thorough classification of blends explains how diverse and complex the nature of blends is. Add to that the wide range of classifications as well as definitions of blends provided by linguists. Overall, given such diversity, some linguists, for instance, categorize blends as a subtype of compounds (for example, Adams, 1973), whereas some other linguists categorize them as a form of shortening (for instance, Cannon, 1986). A blend, according to some linguists like Algeo (1991), is a word-formation device that belongs to the middle area between shortenings, such as clippings and acronyms and fusions like compounds and derivatives (cited in Rúa, 2004). In certain blends, where only one word is shortened while the other remains unchanged, the degree of shortening diminishes, and the blend becomes identical to compounds. Blends, in these cases, can be considered "a bridge between the devices of shortening and compounding" (Rúa, 2004, p. 76).

A key limitation of research on blends, despite their invaluable contributions, is that they do not address the interfaces among the diverse language characteristics. Blends cannot be examined using structural, phonological and/or semantic classification because they vary tremendously (e.g., Bauer, 2012). It is critical to consider the cognitive mechanisms that motivate the formation and processing of blends in order to obtain a deeper understanding of them. To properly investigate blends, it is necessary to be cognizant of how language users process and interpret them (Beliaeva, 2014). In Cognitive linguistics, finding the structure rules shared by all the different language facets is pivotal (Evans \& Green, 2006). A neologism is the product of a uniform procedure in the mind of a speaker, which a hearer simultaneously understands, regardless of which component is prevalent. 
The rich data on the properties of compounds and blends discussed above exhibit not only differences but also commonalities and blurred boundaries. In other words, these word-formation processes belong to different categories, but the border between them is blurred. Compounds and blends thus better fit into shades of grey. Within the taxonomic hierarchy, shown in Table 1, compounds and blends are subordinate level categories, included under the basic level categories. Both combining processes are composed of source words, that is, existing lexical units or grammatical categories in English, notably nouns and adjectives. The source words are the basic level categories based on which compounds and blends are constructed and possibly understood. For instance, the subordinate categories, that is, the compound songwriter and the blend motel, derive from and rely on the basic level categories, that is, the source words song and writer, and motor and hotel, respectively.

Table 1. Exemplification of Compound and Blend Taxonomic Hierarchies

$\begin{array}{ccc}\text { Category Level } & \text { Morphological Taxonomy } & \text { Example } \\ \text { SUPERORDINATE } & \text { WORD-FORMATION } & \\ \text { BASIC LEVEL } & \text { SOURCE WORDS } & \text { song, writer } ; \text { motor, hotel } \\ \text { SUBORDINATE } & \text { COMPOUNDS } & \text { songwriter } \\ & \text { BLENDS } & \text { motel }\end{array}$

Nonetheless, a few compounds and blends relatively rely on source words. For example, the compound coffee house is a type of house or restaurant; however, other beverages and small meals are served in addition to coffee. In the same vein, the blend motorcade (motor + cavalcade) is a type of procession but involves important people. More importantly, some other compounds and blends do not depend on source words. The compound lazybones, for instance, does not denote a bone but a person. In the same vein, the blend cyborg (cybernetic + organism) is not an organism (animal or plant) but a mechanical person or machine. A cyborg is "in science fiction stories, a being that is part human and part, machine or a machine that looks like a human being" (Collins Cobuild English dictionary, 1987). Despite the absence of resemblance between these examples and their source lexemes, English speakers understand them relative to their background knowledge and context.

Compounds and blends have many common and overlapping properties. They, however, contrast since compounds are more prototypical. Compounds are salient in the hearer's mind since they are nearer to the source lexemes. In other words, prototypical compounds consist of the complete forms of the source lexemes, which constitute the most frequent lexical units and are almost faster to recognize as a hearer does not need to speculate about the source words of blended words. For instance, a typical compound like paper clip sounds similar to the source lexemes than a typical blend like bash (bang + smash). A prototypical blend usually consists of a combination of the initial part of a word and the second part of the other word, as in the example of bash. It is worth noting that telescoped blends like shamateur (sham + amateur), which consists of whole lexemes, are an exception to this generalization because they are less prototypical examples of blends.

Overall, the difference between compounds and blends is not absolute but rather gradual. The distinction appears only at the level of form, not meaning. Less salient compounds and less salient blends, as in the example of shamateur discussed above, do not exhibit this difference since they exist in the fuzzy border between central examples of compounds and central examples of blends. As mentioned earlier, the grammatical and morphological differences between compounds and blends concern only the form. When there is a necessity for coining a new word from existing lexemes in 
communication, compounds are created if there is no phonological similarity between their contributing lexemes. However, if there is a phonological similarity between them, they are blended. In producing and perhaps comprehending a blend, both source words are activated (Barlow, 2000). Thus, the classification of regular word-formation processes and 'irregular' word-formation processes (in this paper, compounds and blends) ignores the semantic and conceptual aspects that motivate the creation of these morphological devices. The emphasis on form and formal interpretations, or those derived from the structure of language, lead to a neglect of the role of meaning in language (Brdar, 2017).

The dissimilarities, which are mainly caused by phonological factors, may be explained in terms of metonymy as parts, splinters in the target blend, provide access to wholes (source words) (Lahlou \& Ho-Abdullah, 2012). It is true that a blend is not made up of morphemes "in the sense of recurrent minimal meaningful parts, but of phonological strings that trigger meanings" (Kemmer, 2003, p.77). Compounds and blends are not only a fusion of lexemes or portions of lexemes but also a merging of concepts. In other words, meanings of words merge and so expand to new meanings. Such semantic extension is usually motivated by cognitive mechanisms like image schemas (Johnson, 1987), conceptual metaphor and conceptual metonymy (Lakoff \& Johnson, 2003). The existence of English lexical items like Chunnel and Channel tunnel, bearing the same meaning 'a tunnel under the English Channel', proves the affinity between compounds and blends. In this connection, Turner and Fauconnier (1995) suggest that the difference between the compound Channel tunnel and the blend Chunnel happens by fortuitous accident. The formation of Channel tunnel integrates the conceptual domains of Channel and tunnel. This form further integrates into Chunnel with the presence of the phonemes in Channel and tunnel.

\section{Conclusions}

The purpose of this article was to identify the distinctions and similarities between compounds and blends and to discuss their categorization in the literature. The analysis results show that compounds and blends compare and contrast, with the differences between them becoming blurred gradually. In some ways, typical compounds and typical blends differ, particularly in terms of form or morphological structure, since the first coinage retains the source words, while the second retains only the splinters. As a result, it is possible to conclude that compounds and blends are distributed along a cline that runs from the lexicon to grammar. This conclusion corresponds with Algeo's (1978) observation that the previous work focused on syntax and phonology at the lexicon's expense, although the latter is more important. Being more phonological or syntactic, or more lexical or grammatical, represent different points on the continuum. A cognitive categorization of compounds and portmanteau words, using prototypes and basic level categories, is the best approach to these morphological processes, given that they are the product of conceptual integration. Such a method can provide a more in-depth understanding of neologism construction and comprehension.

\section{Acknowledgement}

The research in this paper is part of a research project funded by Universiti Sains Malaysia Short Term Research Grant.

\section{References}

Adams, V. (1973). An introduction to modern English word-formation. London: Longman. 
Aitchison, J. (2012). Words in the mind: An introduction to the mental lexicon (4 $4^{\text {th }}$ ed.). John Wiley \& Sons.

Algeo, J. (1978). The taxonomy of word making. Word, 29(2), 122-131.

Arnaud, P. J. (2013). Word-formation and word-creation: A data-driven exploration of inventiveness in neologisms. Quaderns de Filologia. Estudis lingüístics, 18, 97-113.

Arndt-Lappe, S., \& Plag, I. (2013). The role of prosodic structure in the formation of English blends. English Language and Linguistics, 17(3), 537.

Aronoff, M. (1976). Word formation in generative grammar. Massachusetts: The MIT Press.

Aronoff, M, \& Anshen, F. (1998). Morphology and the lexicon: lexicalization and productivity. In A. Spencer \& A. Zwicky (Eds.), The Handbook of Morphology. Oxford: Blackwell.

Barlow, M. (2000). Usage, blends and grammar. In M. Barlow \& S. Kemmer (Eds.), Usage-based models of language. California: CSLI.

Bauer, L. (1983). English word-formation. London: Cambridge.

Bauer, L. (1998). Is there a class of neoclassical compounds, and if so is it productive? Linguistics, $36(3)$.

Bauer, L. (2001). Morphological Productivity. Cambridge: Cambridge University Press.

Bauer, L. (2003). Introducing linguistic morphology (2 ${ }^{\text {nd }}$ ed.). Edinburgh: Edinburgh University Press.

Bauer, L. (2006). Compounds and minor word-formation types. In B. Aarts \& A. McMahon (Eds.), The handbook of English linguistics (pp. 483-506). Oxford: Blackwell.

Bauer, L. (2012). Blends. Core and Periphery. In V. Renner, F. Maniez \& P. Arnaud (Eds.), CrossDisciplinary Perspectives on Lexical Blending (pp. 11-22). Berlin: De Gruyter.

Beard, R. (1998). Derivation. In A. Spencer \& M. Z. Arnold (Eds.), The Handbook of Morphology. Oxford: Blackwell.

Beliaeva, N. (2014). Unpacking contemporary English blends: Morphological structure, meaning, processing.

Beliaeva, N. (2019). Blending creativity and productivity: on the issue of delimiting the boundaries of blends as a type of word formation. Lexis. Journal in English Lexicology, (14).

Berlin, B., Breedlove, D.E, Raven, P.H. (2013). Principles of Tzeltal Plant Classification. An Introduction to the Botanical Ethnography of a Mayan-Speaking People of Highland Chiapas. New York and London: Academic Press. (Original work published 1974)

Brdar-Szabó, R., \& Brdar, M. (2008). On the marginality of lexical blending. Jezikoslovlje, 9.

Brdar, M. (2017). Metonymy and word-formation: Their interactions and Complementation. Cambridge: Cambridge Scholars Publishing.

Cannon, G. (1986). Blends in English word formation. Linguistics, 24(4), 725-753.

Collins Cobuild English dictionary. (1987). London: Harper Collins.

Downing, P. (1977). On the creation and use of English compound nouns. Language, 53, 810-842.

Dressler, W. U. (2000). Extra grammatical vs. marginal morphology. Extra grammatical and marginal morphology, 1(11). 
Evans, V., \& Green, M. (2006). Cognitive Linguistics: An Introduction. Edinburgh: Edinburgh University Press Ltd.

Fandrych, I. (2008). Submorphemic elements in the formation of acronyms, blends and clippings. Lexis. Journal in English Lexicology, (2), 103-121.

Geeraerts, D. (2013). Diachronic Prototype Semantics. A Digest. In A. Blank \& P. Koch (Eds.), Historical Semantics and Cognition. Berlin: Mouton de Gruyter. (Original work published 1999).

Ginzburg R. S., Khidekel, S. S., Knyazeva, G. Y., \& Sankin, A. A. (1979). A Course in Modern English Lexicology ( $2^{\text {nd }}$ Ed.). Moscow: Visshaya Shkola.

Gries, S. T. (2004). Isn't that fantabulous? How similarity motivates intentional morphological blends in English. Language, culture, and mind, 415-428.

Gries, S. T. (2012). Quantitative corpus data on blend formation: Psycho-and cognitive-linguistic perspectives. In V. Renner, F. Maniez \& P. Arnaud (Eds.), Cross-Disciplinary Perspectives on Lexical Blending (pp. 145-167). Berlin: De Gruyter.

Hamans, C. (2010). The productivity of blending: Linguistic or cognitive? Or how to deal with administrivia and ostalgia. Lingua Terra Cognita II. A Festschrift for professor Roman Kalisz. Gdańsk: Wydawnictwo Uniwersytetu Gdańskiego, 467-490.

Hamawand, Z. (2011). Morphology in English: Word formation in cognitive grammar. London: Continuum.

Haspelmath, M., \& A. Sims. (2010). Understanding Morphology ( ${ }^{\text {nd }}$ ed). London: Hodder.

Johnson, Mark. (1987). The body in the mind: the bodily basis of imagination, reason and meaning. Chicago: The University of Chicago Press.

Kemmer, S. (2003). Schemas and lexical blends. In H. Cuyckens, T. Berg, R. Dirven \& K.-U. Panther (Eds.), Motivation in language: From case grammar to cognitive linguistics. A Festschrift for Gunter Radden (pp. 69-97). Amsterdam \& Philadelphia: Benjamins.

Lahlou, H., \& Ho-Abdullah, I. (2012). A Cognitive Approach to Compounds and Blends: Revising the linguistic approach to blends. Germany: LAP LAMBERT Academic Publishing.

Lakoff, G., \& Johnson, M. (2003). Metaphors we Live by. Chicago: The University of Chicago Press (Original work published 1980).

Lakoff, G. (2008). Women, Fire, and Dangerous Things: What Categories Reveal about the Mind. Chicago and London: The University of Chicago Press. (Original work published 1987)

Lehrer, A. (1996). Identifying and interpreting blends: an experimental approach. Cognitive Linguistics, 7(4), 359-390.

Lehrer, A. (2007). Blendalicious. In J. Munat (Ed.), Lexical Creativity, Texts and Contexts (pp. 115133). Amsterdam/Philadelphia: John Benjamins Publishing Company.

Mattiello, E. (2013). Extra-Grammatical Morphology in English. Berlin: De Gruyter Mouton.

Plag, I. (2003). Word-formation in English. Cambridge: Cambridge University Press.

Quinion, M. (1996). Through the blender. World Wide Words. Retrieved from http://www.worldwidewords.org/articles/blend.htm 
Renner, V., Maniez, F., \& Arnaud, P. J. (2012). Introduction: A bird's-eye view of lexical blending. In V. Renner, F. Maniez \& P. Arnaud (Eds.), Cross-Disciplinary Perspectives on Lexical Blending (pp. 1-9). Berlin: De Gruyter.

Ronneberger-Sibold, E. (2010, February). Word Creation Definition-Function-Typology. In Variation and Change in Morphology: Selected Papers from the 13th International Morphology Meeting, Vienna, February 2008, 310, p. 201. John Benjamins Publishing.

Rosch, E. (1975). Cognitive Representations of Semantic Categories. Journal of Experimental Psychology: General, 104(3), 192.

Rosch, E., Mervis, C. B., Gray, W. D., Johnson, D. M., \& Boyes-Braem, P. (1976). Basic Objects in Natural Categories. Cognitive psychology, 8(3), 382-439.

Rúa, P. L. (2004). The categorial continuum of English blends. English studies, 85(1), 63-76.

Stekauer, P. (2001). Fundamental principles of an onomasiological theory of English word-formation. Onomasiology Online, 2, 1-42.

Trask, R. L. (1994). Language Change. London: Routledge.

Trommer, J. \& Zimmermann, E. (2012). Portmanteaus as generalized templates. In V. Renner, F. Maniez \& P. Arnaud (Eds.), Cross-Disciplinary Perspectives on Lexical Blending (pp. 233-258). Berlin: De Gruyter.

Turner, M., \& Fauconnier, G. (1995). Conceptual integration and formal expression. Metaphor \& Symbolic Activity, 10(3), 183-204.

\section{AUTHOR BIODATA}

Hicham Lahlou $(\mathrm{PhD})$ is a Senior Lecturer in the English Language Studies department, School of Humanities, Universiti Sains Malaysia. He has more than twenty-two years of experience in teaching high school and university English. His research interests include cognitive linguistics, semantics, morphology and corpus linguistics.

Imran Ho-Abdullah (PhD) is a Professor at the School of Language Studies and Linguistics, Faculty of Social Sciences and Humanities, Universiti Kebangsaan Malaysia. Currently he is Deputy Vice-Chancellor (Industry and Community Partnership) at Universiti Kebangsaan Malaysia. His areas of interest include corpus linguistics, cognitive linguistics, and semantics. 